\title{
Toric Intraocular Lenses for the Correction of Astigmatism
}

\author{
Milorad Milivojević, \\ Miroslav Vukosavljević and Mirko Resan \\ Eye Clinic, Military Medical Academy, Belgrade, \\ Serbia
}

\section{Introduction}

Astigmatism can be corrected with:

1. Glasses and contact lenses

2. Excimer laser refractive procedures (LASIK, PRK)

3. Astigmatic keratotomy

4. Limbal or corneal relaxing and clear corneal incisions

5. Toric intraocular lens

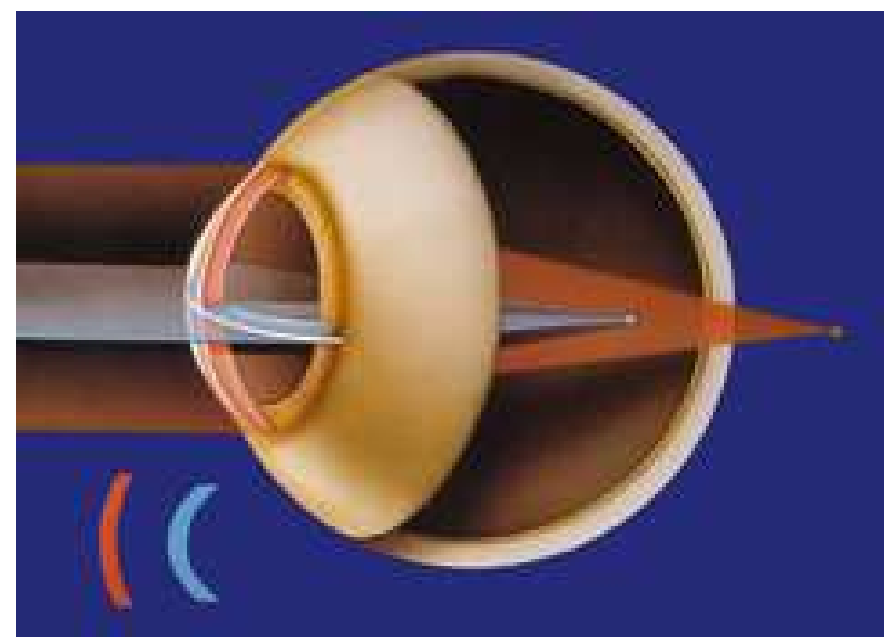

Fig. 1. Eye with astigmatism.

The ideal procedure for the correction of astigmatism should provide: precise and accurate adjustment, safety, predictable outcome, lasting effect and simplicity with an acceptable price. Conventional methods for solving problems such as glasses and/or contact lenses at the present time often do not meet the needs of patients. Whether it is the objective or subjective reasons for a large number of patients tend to avoid wearing glasses or contact lenses. 


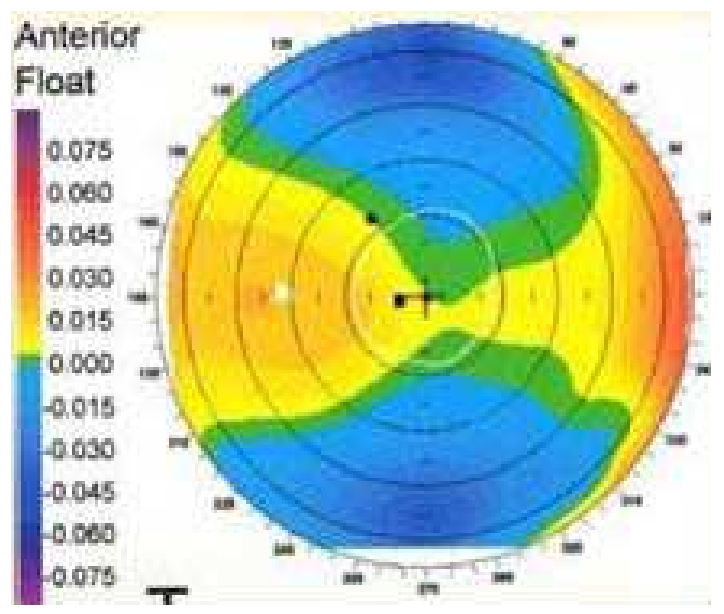

Fig. 2. The topography of corneal astigmatism.

Correcting corneal astigmatism during cataract surgery can increase spectacle independence. For the patient, this has economic benefits as well as desirable cosmetic and practical advantages. Spectacle correction of astigmatism creates meridional magnification, which when coupled with the associated back vertex distance produces retinal images that are asymmetrically magnified and distorted (1).

\begin{tabular}{|l|l|l|l|l|l|}
\hline Company & Intraocular Lens & $\begin{array}{l}\text { Range of Spherical } \\
\text { IOL Power }\end{array}$ & $\begin{array}{l}\text { Range of } \\
\text { Cylindrical } \\
\text { IOL Power }\end{array}$ & $\begin{array}{l}\text { Range of } \\
\text { Corneal } \\
\text { Astigmatism } \\
\text { Able to } \\
\text { Correct }\end{array}$ & $\begin{array}{l}\text { Percentage of } \\
\text { Eyes } \\
\text { Susceptible } \\
\text { to Correction }\end{array}$ \\
\hline Alcon & $\begin{array}{l}\text { AcriSof Toric } \\
\text { SN60T3/T4/T5 } \\
\text { T6/T7T8/T9 }\end{array}$ & +10.0 to $+30.0(0.5)$ & $\begin{array}{l}11.5 \text { to } 6.0 \\
(1.0)\end{array}$ & 1.0 to 4.2 & 34.2 \\
\hline STAAR & $\begin{array}{l}\text { AA4203TF } \\
\text { AA4203TL }\end{array}$ & $\begin{array}{l}+24.0 \text { to }+28.5(0.5) \\
+9.5 \text { to } 23.5(0.5)\end{array}$ & $\begin{array}{l}2 \text { and } 3.5 \\
2 \text { and } 3.5\end{array}$ & $\begin{array}{l}1.4 \text { and } 2.4 \\
1.4 \text { and } 2.4\end{array}$ & $\begin{array}{l}17.1 \\
\text { Human }\end{array}$ \\
Optics & Torica-5 & $\begin{array}{l}-3.0 \text { to }+14.0(1.0) \\
+15.0 \text { to }+25.0(0.5) \\
+26.0 \text { to }+31.0(1.0)\end{array}$ & $\begin{array}{l}2.0 \text { to } \\
12.0(0.5)\end{array}$ & 1.4 to 8.4 & 22.3 \\
\hline Rayner & T- flex 573T/623T & $\begin{array}{l}+6.0 \text { to }+26.0(0.5) \\
-10.0 \text { to }+35.0(0.5)\end{array}$ & $\begin{array}{l}1.0 \text { to } 6.0(1.0) \\
1.0 \\
\text { to } 11.0(0.25)\end{array}$ & $\begin{array}{l}0.7 \text { to } 4.2 \\
0.7 \text { to } 7.7\end{array}$ & $\begin{array}{l}40.5 \\
41.2\end{array}$ \\
\hline Zeiss & $\begin{array}{l}\text { Acri.Comfort643TLC } \\
\text { Acri.Comfort646TLC }\end{array}$ & $\begin{array}{l}0 \text { to }+40.0 \\
-10.0 \text { to }+32.0\end{array}$ & $\begin{array}{l}1.0 \text { to } \\
1.0 \text { to } \\
12.0(0.5)\end{array}$ & $\begin{array}{l}0.7 \text { to } 8.4 \\
0.7 \text { to } 8.4\end{array}$ & $\begin{array}{l}41.2 \\
41.2\end{array}$ \\
\hline
\end{tabular}

Table 1. Range of spherical and cylindrical powers and corneal astigmatism capable of correcting for the toric IOL on the market (1). 
According to the literature, it is estimated that 15 to $22.2 \%$ of patients who are candidates for cataract surgery have astigmatism greater than $1.50 \mathrm{D}$. This indicates that a large number of patients still has blurred vision after cataract surgery due to residual astigmatism and require operative correction of distance vision glasses or lenses. $(2,3)$. Since the corneal limbal relaxing incision often have an unpredictable effect on the postoperative visual acuity, and the use of Excimer laser refractive surgery is often not feasible because of it is often contraindicated in elderly people, expensive procedure, requires high technological equipment and expertise of medical personnel. Toric intraocular lenses are the correction of choice for high levels of astigmatism. They promise a predictable method of astigmatic correction with minimal impact to the cornea. However, the effectiveness of a toric IOL is dependent on its orientation. $(1,4)$

\section{Surgical aspects of implantation of toric intraocular lenses}

Cataract surgery with implantation of toric intraocular lenses is identical to the normal procedure and requires no special training (4). The difference is reflected in the preoperative treatment, and in celebration of the cylinder axis, which is adjusted to the patient's eye. Toric IOLs need precise positioning to achieve optimal visual results. In accordance with the corneal measurements, reference markers on opposite sides of the pupil need to be established to demarcate the correct axis for IOL orientation. Eye rotation occurs in a supine position and so these markers need to be established pre-operatively. The slit lamp beam axis graticule can be dialed to the correct axis or a bespoke eyepiece graticule can be used to determine where to place the markers, which can be applied to the cornea or conjunctiva using ink or with scratches. Ink should be applied at the last possible minute as it can diffuse by $10^{\circ}$ or disappear before implantation is complete. As an alternative, a Neodymium:Yttrium-Aluminum-Garnet (Nd:YAG) laser can be used to mark the cornea. It has been suggested that this improves the accuracy and definition of the markers. Specific toric axis marking instruments exist. One step methods, such as the Devgan Axis Marker (Accutome, Pennsylvania, USA) and the Gerten Pendulum Marker (Geuder, Heidelberg, Germany) are used pre-operatively to determine the required axis. They are dependent on a vertical head position when applied to the cornea. Two-step methods require marking the cornea at the zero and 180 degree positions pre-operatively and then aligning a degree gauge with these markings intra-operatively to establish the correct position (1). The iris architecture is intricate and full marking is done manually or by using the instrument in a sitting position $(1,5)$. Another difference lies in the fact that the shaft of toric IOL to coincide with the axis of the cylinder, marked preoperatively. This is achieved by the end of the operation during the removal of viscoelastic. There are two main surgical factors that can influence IOL rotation. In the early post-operative period careful wound construction is essential. Following surgery, the IOP can fluctuate and in 6.3 per cent of patients, it drops to below $5 \mathrm{mmHg}$. It is important to emphasize that it is necessary to remove viscoelastic a rotation for maximum stability. Viscoelastic lag could lead to undesirable postoperative implant rotation, and therefore should be brought into question and the desired outcome (1).

Consideration of IOL haptic design is very important when trying to prevent postoperative lens rotation. Over time, the capsular bag contracts to enclose and secure the IOL, however, 
before this contraction occurs there is potentfor rotation (6). To prevent rotation immediately after implantation, it is important to maximize the contact between the IOL haptic and the capsular bag. A polymethyl methacrylate (PMMA) IOL creates the most friction with the bag, followed by acrylic, with silicon causing the least (7). It is believed that if the implant rotates by more than 30 degrees postoperatively, the effect of cylindrical lenses is lost. The third difference relates to the calculation of the refractive lens, the strength and axis cylinder. As a rule, keratometry very carefully set manually, not automatic keratometer. Must also be taken into account and astigmatism, which will occur as a consequence of the main corneal incision. IOL manufacturers have developed calculators to determine the refractive power lens (as spherical and cylindrical components), and determine the shaft in which the implant should be placed. The data are entered to the calculator are manually specified value keratometry, spherical components required strength, where you are planning a major incision. These calculators are easily and freely available for use on the Internet (8).

\section{The outcome of intraocular implantation of toric IOL}

When it comes to the outcome of implantation of toric intraocular lenses, it is essential to assess the following parameters:

\subsection{Rotational stability in capsular bag}

\subsubsection{Plate haptic IOLs}

Plate haptic IOLs demonstrate excellent long-term stability. In comparison with open-loop haptics, plate haptic IOLs are not as susceptible to the effects of compression from the capsular bag.

The first commercially available toric IOL was the STAAR 4203TF (STAAR Surgical, Company, California, USA), which achieved FDA approval in 1998. It is a biconvex, silicone, plate haptic toric IOL, $10.8 \mathrm{~mm}$ in length, with two 1.15-mm positioning holes. The lens is available with a torus of either 2.00 or $3.50 \mathrm{D}$, which corrects levels of corneal astigmatism between 1.50 and $3.50 \mathrm{D}$. The lens demonstrates excellent long-term stability once fixation within the capsular bag has been established, 30 however, in the early postoperative period, the lens demonstrates a relatively high incidence of rotation. In its FDA trial, 24 per cent of the lenses rotated more than $10^{\circ}, 12$ per cent more than $20^{\circ}$ and 8 per cent more than $30^{\circ}(9)$.

The AT-TORBI (Carl Zeiss Meditec, Berlin, Germany) (previously the ACri comfort toric IOL) is an acrylic, bi-toric, plate haptic IOL, $11 \mathrm{~mm}$ in length, possessing two positioning holes on the haptic. It is a microincisional lens, and it can be inserted through a $1.5-\mathrm{mm}$ incision. The AT-TORBI has a 6.0-mm optic, and can correct high levels of astigmatism, as it is available with a torus of 1.00 to $12.00 \mathrm{D}$ in $0.50-\mathrm{D}$ steps. Large-scale studies are required to demonstrate the effectiveness of this lens but early results are very promising. In a pilot study involving 21 eyes with 2.00 to $9.00 \mathrm{D}$ of corneal astigmatism, only one lens rotated more than $5^{\circ}$ between day one and six months post-operatively, with 76.1 per cent of these subjects achieving a postoperative uncorrected vision of 20/40 or better (10). 

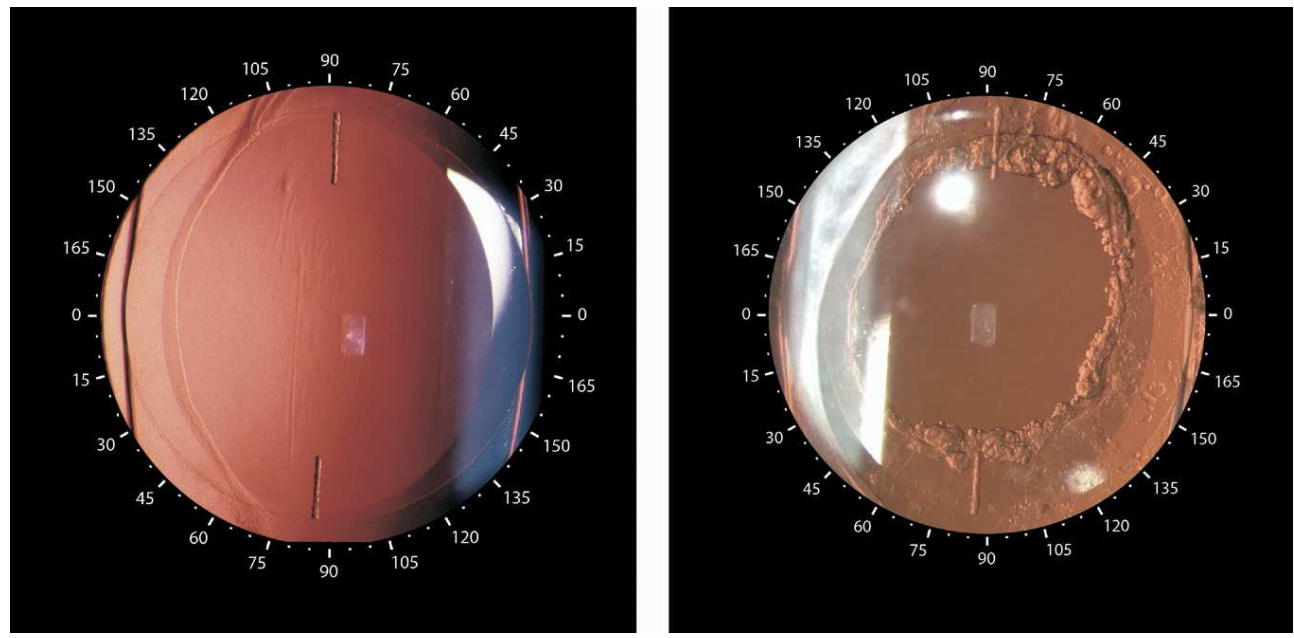

Fig. 3. Slit-lamp retroillumination photographs of a Staar toric intraocular lens with a superimposed digital protractor before (left) and after (right) a circular neodymiumyttrium-aluminum-garnet posterior capsulotomy (9).

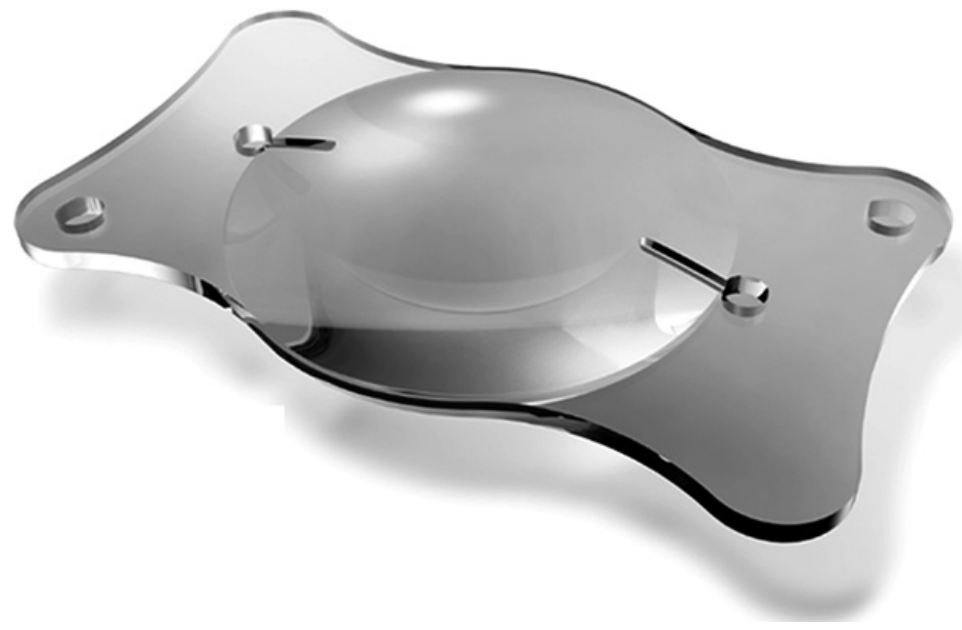

Fig. 4. The ACri comfort toric IOL (10). 


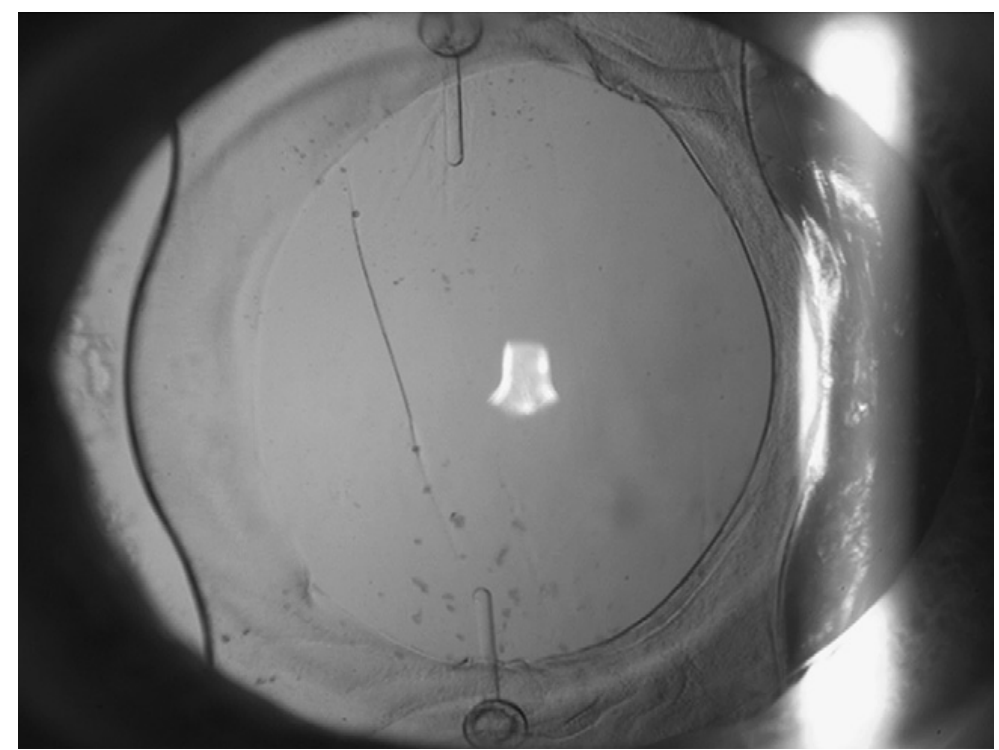

Fig. 5. The ACri comfort toric IOL in situ 3 months postoperatively (10).

\subsubsection{Open loop haptic lenses}

Open loop haptic lenses compared with previous models (plate haptic IOLs) demonstrate excellent early rotational stability in comparison to plate haptics. The longer loop haptics ensure immediate contact between haptic and capsular bag, maximizing friction in the early postoperative period, however, they are susceptible to late rotation caused by the compression of the capsular bag (11).

The AcrySof toric IOL (Alcon, Fort Worth, USA) is a single-piece acrylic toric IOL with open loop L-shaped haptics. It has a posterior toric surface with three available toric powers 1.50, 2.25 and $3.00 \mathrm{D}$. It is a $13 \mathrm{~mm}$ in length with a $6.0 \mathrm{~mm}$ optic. The AcrySof toric has demonstrated excellent rotational stability results. During its FDA trial, $81.9 \%$ of lenses rotated less than $5^{\circ}$ and only $2.9 \%$ rotated over $10^{\circ}$ and only $0.8 \%$ of these lenses were repositioned $(2,8)$.

The Torica S (Human Optics, Erlangen, Germany) otherwise known as the Microcyl Toric 6116 (Human Optics), is a three-piece, silicon, Z-shaped open loop haptic toric IOL. It is $11.6 \mathrm{~mm}$ in length with a $6.0 \mathrm{~mm}$ optic. The Torica $S$ has a novel haptic design with undulations designed to increase the friction between lens and bag. It has been reported that these undulations maintain the IOLs position but make it difficult to rotate the lens within the bag. To prevent the haptic undulations from causing trauma when rotating the lens, it is recommended that they are compressed against the optic and held away from the capsular bag until the lens is in the required position. In a study of 21 eyes (14 subjects) no lens rotated more than $5^{\circ}(12)$. 


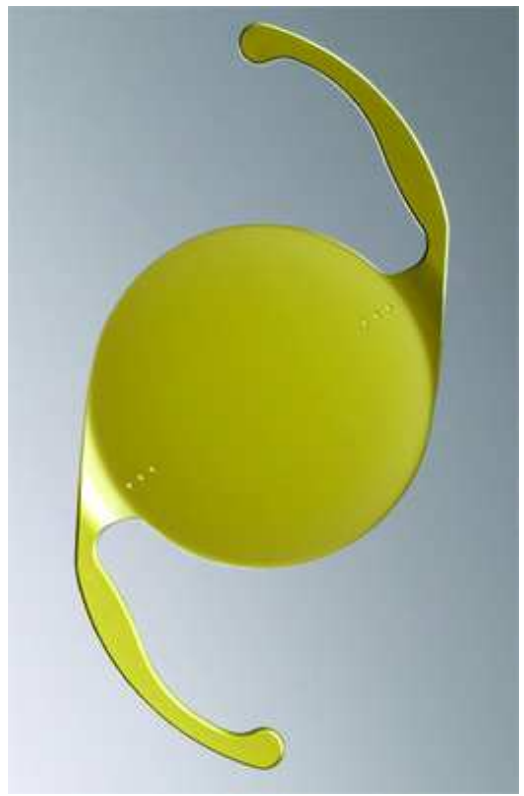

Fig. 6. AcrySof toric IOL.

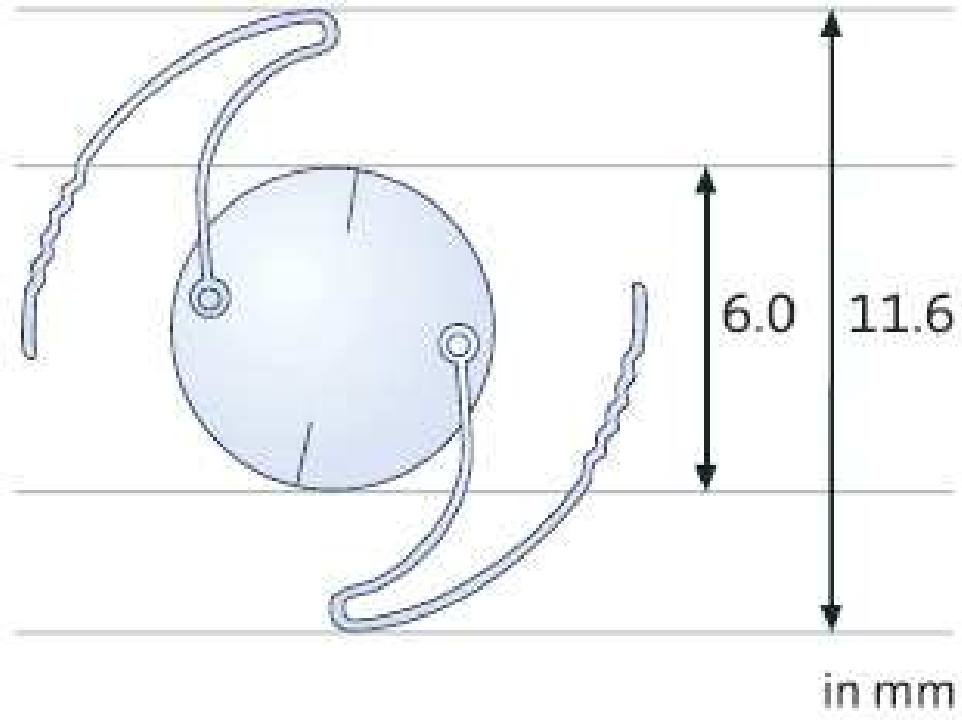

Fig. 7. The Torica-S IOL. 


\subsubsection{Closed loop haptics IOLs}

Closed-loop haptics are a relatively new addition to the toric IOL market. These lenses are typically longer than the plate haptics, which should give good initial contact. The loops have a second insertion on the IOL that may resist capsular compression.

The T-flex toric (Rayner, Hove, UK) is a single-piece, acrylic, closed-loop haptic with antivaulting haptic technology. It is available in two sizes; the $573 \mathrm{~T}$ has a $5.75-\mathrm{mm}$ optic and 12 mm haptics, and the $623 \mathrm{~T}$ has a $6.25-\mathrm{mm}$ optic and $12.5 \mathrm{~mm}$ haptic. The anterior surface of the optic houses the toric surface, which is available with a torus of one to $11 \mathrm{D}$. The antivaulting haptic technology is designed to reduce the effect of compression using a lock and key system. Compression will push the outside of the haptic against the inner haptic, locking it into place. It has been reported that in a group of 10 subjects no lens rotated more than $5^{\circ}$ between one week and two years after implantation (13).

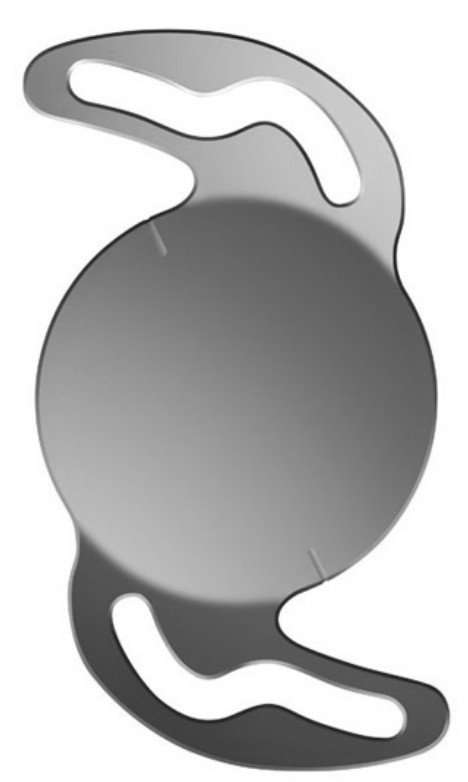

Fig. 8. Rayner T-flex ${ }^{\circledR}$ Aspheric Toric IOL.

The Akreos (Bausch \& Lomb, Rochester, USA) aspheric platform is a single piece acrylic, closed loop haptic IOL. It has a $6.0-\mathrm{mm}$ optic and is $11 \mathrm{~mm}$ in length with a $360^{\circ}$ square edge. The IOL is currently being assessed for its viability as a platform for housing a toric surface. A multicenter study has examined the rotational stability of the Akreos haptic housing from one day to six months post-operatively in 97 eyes. This lens was shown to be stable, as 96 per cent of the IOLs rotated no more than $5^{\circ}$ and $99 \%$ no more than $10^{\circ}$ (14). 


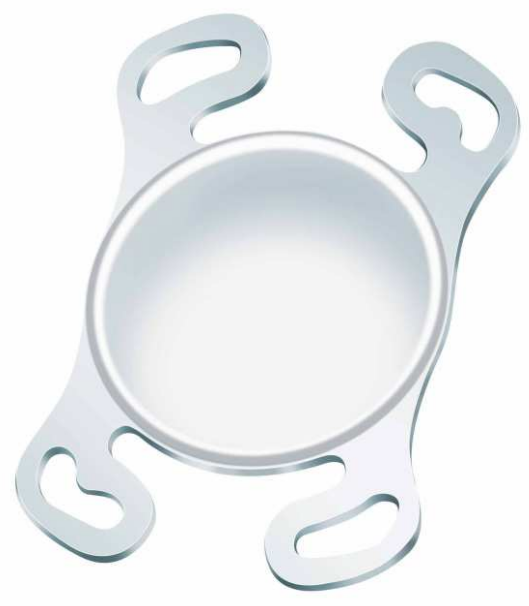

Fig. 9. Akreos ${ }^{\mathrm{TM}}$ aspheric IOL.

Tsinopoulos and colleagues (15) reported a new procedure for intra-operative toric intraocular lens (IOL) axis assessment in order to achieve optimal implantation. IOL implantation procedure was directly recorded. An assessor estimated the angle formed by the marked 0-180 axis and the toric IOL axis after implantation with the use of the appropriate software. If IOL implantation was assessed to be inaccurate, the surgeon was advised to correct IOL positioning by rotating the IOL clockwise. The assessment procedure was repeated until accurate IOL positioning was achieved.

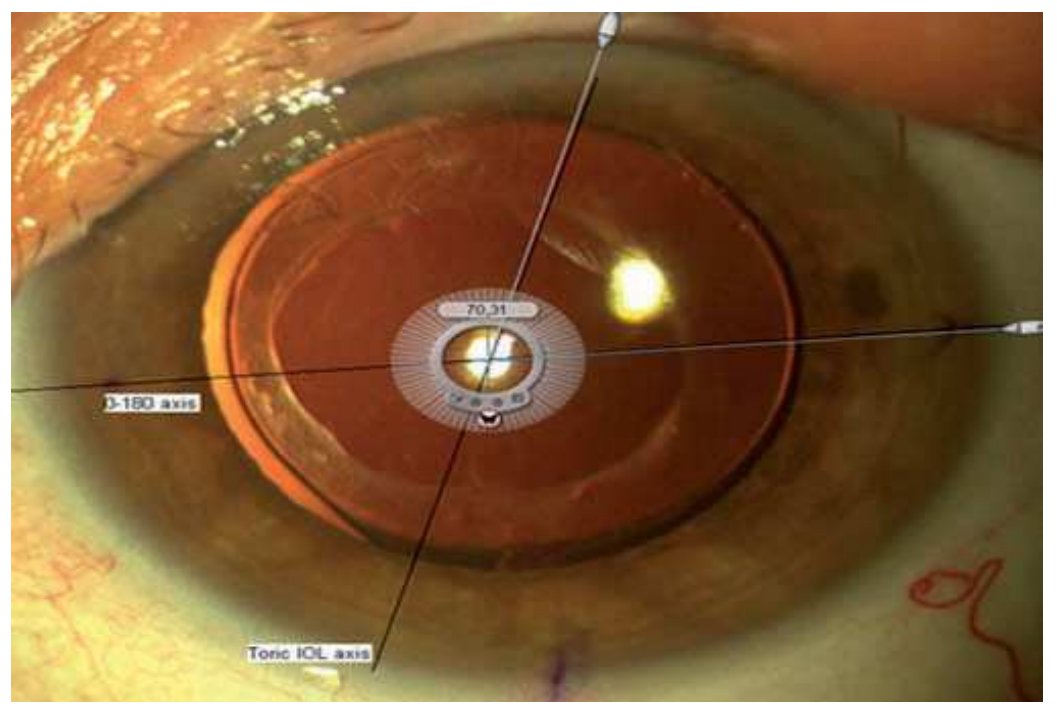

Fig. 10. Intra-operative toric implantation assessment with the use of the appropriate software (15). 


\subsection{The reduction of absolute residual astigmatism}

The average absolute residual astigmatism after implantation of toric intraocular lenses is less than 0.55D. In patients who have significant astigmatism, and implanted them classic spherical lenses residual astigmatism is an average of $1.22 \mathrm{D}(1)$.

\subsection{Uncorrected visual acuity at distance}

Ninety-four percent of patients achieve visual acuity $\geq 0.5$ with no correction, which is a remarkable result. Also, these patients have a greater vision improvement at all levels compared with patients who have conventional spherical lens. In $97 \%$ of patients whose toric lenses implanted in both eyes maximize distance vision without correction $(1,2)$.

\subsubsection{Stability and predictability of outcome}

Patients who have significant astigmatism after cataract surgery have the option for correcting glasses or contact lenses. However, for many patients who expect excellent postoperative vision this is unacceptable solution.

Relaxing incisions that had previously been strongly represented in the correction of astigmatism now use fewer surgeons (40\%) for the following reasons:

- Unpredictable results in a significant number of cases

- The problem of regression, astigmatism, especially in patients with severe preoperative astigmatism

- Inability to correct high astigmatism

- Paracentral incisions can correct high astigmatism, but more complications

- Healing of incisions can be problematic, since it is predominantly an elderly patient

- Patients with steep corneas and asymmetriastigmatism are not good candidates $(1,16)$.

When speaking of the Excimer laser for the correction of astigmatism, the method is effective and safe, but laser is expensive and this way the correction is often unavailable for most patients (17).

\subsubsection{Economic evaluation of toric intraocular lens}

Pineda and colleagues (18) assessed the economic value of improved uncorrected visual acuity among patients with cataract and preexisting astigmatism treated with toric intraocular lenses (IOLs) compared with conventional monofocal IOLs. They concluded that toric IOLs reduce lifetime economic costs by reducing the need for glasses or contact lenses following cataract removal. These results can inform physicians and patients regarding the value of toric IOLs in the treatment of cataract and preexisting astigmatism.

Laurendeau and collegues (19) in their study concluded that bilateral toric IOL implants in astigmatic patients decreased spectacle dependence for distance vision and the need for complex spectacles. The economic consequences for patients depended on the national spectacle costs usually incurred after cataract surgery. 


\section{Conclusion}

Toric intraocular lenses are accurate, reliable, predictable, permanently correcting astigmatism in cataract patients who are operated, while the flow of the operation is not extended, or require special training for surgeons already trained. Rotational stability of an IOL is the primary determinant of the refractive outcome. The surgeon should also keep in mind that the final outcome is very important and proper selection of patients, including patients with irregular astigmatism due to the scar tissue forming of the cornea, keratoconus, pellucid marginal degeneration, etc,. New available aspheric toric lens offer a better quality of vision postoperatively (reduction of spherical aberration, further improving contrast sensitivity, and uncorrected visual acuity at a distance). Toric IOLs reduce lifetime economic costs by reducing the need for glasses or contact lenses following cataract removal.

\section{References}

[1] Buckhurst PJ. Wolffsohn JS. Davies LN, Naroo SA. Surgical correction of astigmatism during cataract surgery. Clin Exp Optom 2010; 93: 409-418.

[2] Bauer NJC, De Vries NE, Webers CAB, Hendrikse F, Nuijts RMMA. Astigmatism management in cataract surgery with the AcrySof toric intraocular lens. J Cataract Refract Surg 2008; 34:1483-1488.

[3] Masket S, Wang L, Belani S. Induced astigmatism with 2.2- and 3.0-mm coaxial phacoemulsification incisions. J Refract Surg 2009; 25: 21-24.

[4] Amesbury EC, Miller KM. Correction of astigmatism at the time of cataract surgery. Curr Opin Ophthalmol 2009; 20: 19-24.

[5] Graether JM. Simplified system of marking the cornea for a toric intraocular lens. J Cataract Refract Surg 2009; 35: 1498-1500.

[6] Patel CK, Ormonde S, Rosen PH, Bron AJ. Postoperative intraocular lens rotation: a randomized comparison of plate and loop haptic implants. Ophthalmology 1999; 106: 2190-2195.

[7] Oshika T, Nagata T, Ishii Y. Adhesion of lens capsule to intraocular lenses of polymethylmethacrylate, silicone and acrylic foldable materials: an experimental study. Br J Ophthalmol 1998; 82: 549-553.

[8] AcrySof Toric Single-Piece Natural IOL Product Information. Fort Worth, TX: Alcon Laboratories, Inc.; 2005.

[9] Jampaulo M, Olson MD, Miller KM. Long-term Staar toric intraocular lens rotational stability. Am J Ophthalmol 2008; 146: 550-553.

[10] Alio JL, Agdeppa MCC, Pongo VC, Kady BE. Microincision cataract surgery with toric intraocular lens implantation for correcting moderate and high astigmatism: pilot study. J Cataract Refract Surg 2010; 36: 44-52.

[11] Chang DF. Comparative rotational stability of single-piece open-loop acrylic and platehaptic silicone toric intraocular lenses. J Cataract Refract Surg 2008; 34: 1842- 1847.

[12] De Silva DJ, Ramkissoon YD, Bloom PA. Evaluation of a toric intraocular lens with a Zhaptic. J Cataract Refract Surg 2006; 32: 1492-1498.

[13] Narendran R, Vyas A, Bacon P. Centration, rotational stability and outcomes of Rayner T-flexTM toric lens implantation: 2 year results. Proceedings of the XXVII congress of the ESCRS, Barcelona, 2009. 
[14] Buckhurst PJ, Wolffsohn JS, Naroo SA, Davies LN. Rotational and centration stability of an aspheric intraocular lens with a simulated toric design. J Cataract Refract Surg 2010; 36: 1523-1528.

[15] Tsinopoulos IT, Symeonidis C, Tsaousis KT, Tsakpinis D, Ziakas NG, Dimitrakos SA. Intra-operative assessment of toric intra-ocular lens implantation. Indian J Ophthalmol 2011; 59: 60-62.

[16] Kaufmann C, Peter J, Ooi K, Phipps S, Cooper P, Goggin M. Limbal relaxing incisions versus on-axis incisions to reduce corneal astigmatism at the time of cataract surgery. J Cataract Refract Surg 2005; 31: 2261-2265.

[17] Sanders DR, Sanders ML. Comparison of the toric implantable collamer lens and custom ablation LASIK for myopic astigmatism. J Refract Surg 2008; 24: 773-778.

[18] Pineda R, Denevich S, Lee WC, Waycaster C, Pashos CL. Economic evaluation of toric intraocular lens. Arch Ophthalmol. 2010; 128: 834-840.

[19] Laurendeau C, Lafuma A, Berdeaux G. Modelling lifetime cost consequences of toric compared with standard IOLs in cataract surgery of astigmatic patients in four Europian countries. Journal of Medical Economics 2009; 12: 230-237. 


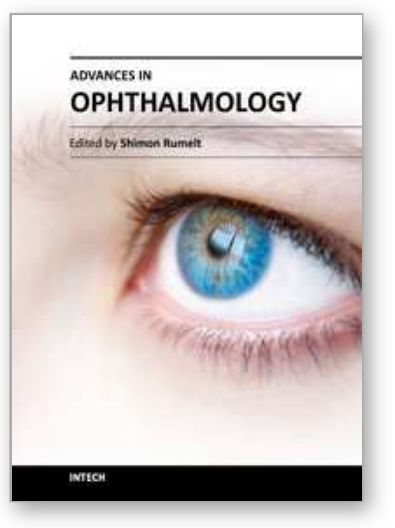

\author{
Advances in Ophthalmology \\ Edited by Dr Shimon Rumelt
}

ISBN 978-953-51-0248-9

Hard cover, 568 pages

Publisher InTech

Published online 07, March, 2012

Published in print edition March, 2012

This book focuses on the different aspects of ophthalmology - the medical science of diagnosis and treatment of eye disorders. Ophthalmology is divided into various clinical subspecialties, such as cornea, cataract, glaucoma, uveitis, retina, neuro-ophthalmology, pediatric ophthalmology, oncology, pathology, and oculoplastics. This book incorporates new developments as well as future perspectives in ophthalmology and is a balanced product between covering a wide range of diseases and expedited publication. It is intended to be the appetizer for other books to follow. Ophthalmologists, researchers, specialists, trainees, and general practitioners with an interest in ophthalmology will find this book interesting and useful.

\title{
How to reference
}

In order to correctly reference this scholarly work, feel free to copy and paste the following:

Milorad Milivojević, Miroslav Vukosavljević and Mirko Resan (2012). Toric Intraocular Lenses for the Correction of Astigmatism, Advances in Ophthalmology, Dr Shimon Rumelt (Ed.), ISBN: 978-953-51-0248-9, InTech, Available from: http://www.intechopen.com/books/advances-in-ophthalmology/toric-intraocular-lenses-for-thecorrection-of-astigmatism

\section{INTECH}

open science | open minds

\section{InTech Europe}

University Campus STeP Ri Slavka Krautzeka 83/A 51000 Rijeka, Croatia

Phone: +385 (51) 770447

Fax: +385 (51) 686166 www.intechopen.com

\section{InTech China}

Unit 405, Office Block, Hotel Equatorial Shanghai No.65, Yan An Road (West), Shanghai, 200040, China 中国上海市延安西路65号上海国际贵都大饭店办公楼405单元 Phone: +86-21-62489820

Fax: +86-21-62489821 
(C) 2012 The Author(s). Licensee IntechOpen. This is an open access article distributed under the terms of the Creative Commons Attribution 3.0 License, which permits unrestricted use, distribution, and reproduction in any medium, provided the original work is properly cited. 